\title{
TRADUÇÃO \\ Anticapital para o século XXI (sobre a metacrise do capitalismo e as possibilidades abertas para a política radical) 1
}

Albena Azmanova²

Resumo: Tomando o caráter moderado dos protestos sociais recentes como seu ponto de partida, esta análise investiga as democracias liberais em seu estado atual, um estado em que a suposta crise do capitalismo entrou, ela própria, em crise - uma condição social de metacrise, marcada pela ausência de energias utópicas e da prospectiva de uma revolução -, ao mesmo tempo que a sociedade experiencia a si mesma em crise perpétua. Esta investigação apreende, então, o potencial de mudança radical pelo prisma da subversão do capitalismo (e não da derrubada dele ou da resistência a ele) através de práticas que combatam a própria dinâmica constitutiva do capitalismo - a produção de lucro.

Palavras-chave: capitalismo; crise; democracia; emancipação; hegemonia; marxismo; neoliberalismo; política radical.

\section{A insustentável leveza dos protestos sociais}

"Caríssimo burguês, perdão pelo incômodo, poderíamos todos, por favor, viver dignamente?" - pleiteava um lema dos Coletes Amarelos, movimento de base por justiça econômica que surgiu na França, em outubro de 2018, protestando contra um planejado aumento dos preços de combustíveis. Ele se expandiu rapidamente, a ponto de tornar-se o movimento de protesto de mais longa duração e de maior intensidade nas democracias ocidentais no início do século XXI. De maneira semelhante, o movimento espanhol dos Indignados, que mobilizou cerca de oito milhões de pessoas na primavera de 2011, levantou uma reivindicação por uma política decente, num protesto contra a imposição das políticas de austeridade que se seguiram ao colapso financeiro de 2007-2009 e à consequente crise dos fundos soberanos. Injuriados pelas altas taxas de desemprego, pelos cortes no bem-estar social e pelo resgate dos bancos, resgate que devorou o orçamento nacional, os jovens espanhóis clamaram: “Nós não somos contra o sistema, o sistema é contra nós!".

1 Artigo original: Azmanova, A. (2020). Anti-capital for the XXIst century (on the metacrisis of capitalism and the prospects for radical politics). Philosophy and Social Criticism, 46 (5), pp. 601 612. DOI: https://doi.org/10.1177/0191453720905862. Tradução de José Ivan Rodrigues de Sousa Filho (PPGFil/Universidade Federal de Santa Catarina). 0 tradutor agradece à autora por seus esforços para obter a permissão para traduzir o original junto à editora SAGE, titular dos direitos autorais; à Universidade de Kent pelo financiamento da permissão; e a um(a) parecerista anônimo(a) pela revisão minuciosa e enriquecedora. (N. T.)

2 Universidade de Kent, Bélgica. 
Na década passada, os protestos sociais foram amplos, espirituosos e fracos. Ao mesmo tempo que as insurgências nas ruas e nas praças deram voz a uma frustração social ubíqua, elas também revelaram o caráter notavelmente não radical desses protestos populares, que buscaram, mais que tudo, recuperar a relativa igualdade de prosperidade que marcara os anos dourados do Estado de bem-estar social. ${ }^{3} \mathrm{Se}$ o saldo imediato da crise financeira gerou certa conversa sobre uma crise terminal do capitalismo (o Financial Times rodou uma série de artigos intitulada "Capitalismo em crise" no início de 2012), os discursos de crise sistêmica foram rapidamente substituídos por queixas sobre a desigualdade crescente e reivindicações pela tributação dos ricos - uma demanda substancialmente mais tímida que a abolição de um sistema que inflige danos multifacetados aos indivíduos, a suas comunidades e a seu ambiente natural. O caráter taciturno da política de protestos contemporânea é indicador de uma condição peculiar em que as democracias liberais se encontram atualmente, um estado que passarei a descrever como a metacrise do capitalismo democrático.

\section{O escândalo da democracia e a sobrevivência do neoliberalismo como morto-vivo}

A irrupção de protestos antissistema na década seguinte à crise econômica de 2008-2009 fraturou, de fato, a ordem neoliberal, provocando a busca por alternativas. Ela pôs fim à hegemonia neoliberal, quer dizer, eliminou a certeza com que a combinação neoliberal de mercados livres e economias abertas era tida como a fórmula inconfundivelmente razoável, a única fórmula pensável, para as políticas públicas. Nas duas últimas décadas do século $X X$, essa hegemonia havia sido lograda através de uma acomodação ideológica entre as elites políticas de centro-esquerda e centro-direita. A centro-esquerda aceitara o capitalismo de livre mercado, ao passo que a centro-direita adotara a agenda da New Left de não discriminação, reconhecimento identitário e preocupações ecológicas. Esse acordo forjara o que Nancy Fraser chama de "neoliberalismo progressista" - o que não quer dizer que essa forma de capitalismo seja inerente e indubitavelmente progressista, mas que ela incorporara elementos da política progressista exatamente para alcançar uma posição hegemônica baseada no amplo apoio das forças políticas dominantes (Fraser, 2017a, 2017b).

Os protestos antissistema da década passada, que foram erroneamente rotulados de populismo (Azmanova, 2018a, 2019), reacenderam o conflito partidarista

\footnotetext{
3 A lista original de 42 reivindicações dos Coletes Amarelos incluía predominantemente preocupações com o custo de vida (desde a redução da tributação sobre os combustíveis e o aumento do salário mínimo até a gratuidade do estacionamento no centro das cidades e a correção das aposentadorias pela inflação): https://www.opendemocracy.net/en/can-europe-make-it/demands-of-francesyellow-vests-as-uploaded-by-france-bleu-november-29/ (acesso em: 9 abr. 2020).
} 
e, posteriormente, despiram o véu de inevitabilidade que possibilitara a hegemonia neoliberal. Esses protestos abriram o que Chantal Mouffe e Ernesto Laclau chamam de um "espaço de indeterminação" - a possibilidade de mudança sem um télos definido, sem uma direção preestabelecida. Poderão as forças políticas progressistas canalizar o crescente descontentamento social, dando-lhe uma direção?

0 primeiro obstáculo ao projeto da política progressista é o fato de que o fraturamento da hegemonia neoliberal não extirpou completamente o capitalismo neoliberal. Apesar da copiosa retórica política sobre mudança, o grosso das políticas públicas que desencadearam o colapso financeiro dez anos atrás ainda está em vigor. Isso ocorre porque a motivação das políticas públicas e a mentalidade política do neoliberalismo permanecem intactas. A motivação das políticas públicas do neoliberalismo é a busca da competitividade nacional na economia global como prioridade máxima para as políticas públicas (superando, por exemplo, o crescimento ou o emprego), o que implica a intensificação da desregulação da economia nacional. A liberalização dos mercados de consumo e de trabalho persiste, ao mesmo tempo que se deflagram guerras comerciais. À exceção dos esforços para elevar o salário mínimo, não há qualquer empenho para restringir o reinado do livre mercado sobre as economias nacionais, pois se crê que isso prejudicaria a competitividade dessas economias no mercado global. Já a mentalidade política do neoliberalismo consiste em eximir o Estado de responsabilidade social, descarregando essa responsabilidade (por tornarmo-nos empregáveis e continuarmos empregados e por proteger o meio ambiente, por exemplo) nos indivíduos e em suas comunidades. Essa delegação de responsabilidade também se manifesta sob a forma de demanda por mais democracia. Assim, para empregar a análise que Jodi Dean faz de nosso capitalismo contemporâneo, "comunicativo", a democracia se torna uma fantasia neoliberal. ${ }^{4}$

Além disso, a democracia, cativa do encantamento da prosperidade, tornouse um eficiente instrumento do estabelecimento jurídico do capitalismo neoliberal. O mecanismo das eleições democráticas confere existência política, sob a forma de coalizões de governo com mandato democrático, à poderosa aliança entre capital e trabalho que advoga as mesmas políticas públicas de competitividade nacional (desregulação dos mercados de trabalho e dependência de combustíveis fósseis baratos, por exemplo) que minam as políticas públicas comprometidas com a justiça social e a justiça ambiental. Como a rede da seguridade social tem sido continuamente reduzida, a dependência que os indivíduos têm do emprego como uma fonte de sustento aumentou. Em consequência, a agenda de políticas públicas em favor dos empregos e do crescimento veio a fornecer o senso comum político através do qual

\footnotetext{
$4 \mathrm{Na}$ abordagem de Dean, nosso "capitalismo comunicativo" é prenhe de ideais de inclusão e participação, e uma profusão de arranjos de alta tecnologia torna mais fácil do que nunca que a voz do indivíduo seja ouvida. Porém, não só essa participação democrática deixa o capitalismo intacto, mas também o capitalismo emprega a democracia em sua própria reprodução (Dean, 2009).
} 
capital e trabalho se unem em apoio à hegemonia neoliberal. ${ }^{5}$ Assim, mesmo no fundo do poço do colapso financeiro, o voto democrático tendeu a ir quer para a centro-direita, que fora a principal autora das políticas públicas que inauguraram a transição neoliberal nos anos 1980 (privatização do patrimônio público e desregulação da economia), quer para a extrema-direita, que não causa qualquer problema sério para o neoliberalismo. A extrema-direita transforma o conflito entre os imperativos capitalistas de crescimento e os imperativos sociais de integração num conflito entre "nosso" capitalismo nacional (nossos empregos e nosso crescimento) e o capitalismo global “deles”. Essas tensões econômicas são politizadas ainda mais sob a forma de tensões culturais (medo de imigrantes que nos privam de nossos empregos e, ao mesmo tempo, erodem nossa coesão cultural), constituindo um fenômeno novo que trato como "xenofobia econômica" (Azmanova, 2011a).

Ao longo desse processo, as instituições da participação democrática não apenas são enfraquecidas; elas são usadas, de fato, para promover o apoio às próprias políticas econômicas que causam o mal-estar social através da precarização do trabalho e do minguamento da seguridade social e do orçamento para serviços públicos. Defrontamo-nos, assim, com o que podemos chamar de "escândalo da democracia" (à semelhança do "escândalo da razão", uma noção de Immanuel Kant) ${ }^{6}$ - por mais que dependamos da democracia para que nos poupemos dos efeitos mais nefastos do capitalismo, a política democrática torna-se, ainda que acidentalmente, o mecanismo que estabelece juridicamente a lógica do capitalismo. Essa é a razão pela qual, sob o arcabouço da democracia capitalista, as forças políticas progressistas sempre se defrontarão com o dilema de ou servir aos interesses de curto prazo que seu eleitorado tem em perpetuar a dinâmica de acumulação de capital, da qual depende a sorte do "homem comum"; ou servir ao interesse social de longo prazo em proteger os seres humanos e o ambiente natural justamente daquela dinâmica.

Em consequência da perpetuação das mesmas políticas públicas que causam a experiência de crise, o neoliberalismo escapole de sua morte. Ele nem está plenamente recuperado, nem está sendo substituído por um modelo alternativo. Ele se encontra em estado de morto-vivo.

\footnotetext{
5 A esse respeito, é revelador o papel desempenhado pelos sindicatos alemães no estabelecimento jurídico do Plano Hartz de 2002, destinado à liberalização do mercado de trabalho, aceitando, em prol da preservação dos empregos, o aumento das horas de trabalho e a diminuição da remuneração (Odendahl, 2017). Essa cumplicidade entre trabalho e capital precede à reforma Hartz e não se restringe à Alemanha (ver Rhodes, 2001; Streeck, 1984). Essa é uma ilustração perfeita do processo de geração do que Michel Foucault descreve como "governamentalidade" - o poder produz os sujeitos adequados a seu governo.

6 Kant nota que, por causa do "escândalo da ostensiva contradição da razão consigo mesma", ao mesmo tempo que a mente humana é incapaz de um conhecimento certo e verificável, somos invariavelmente compelidos a buscar tal conhecimento (Kant, 1967, p. 252; 2007 [1781], pp. 31-2, 34). Já eu discuto os efeitos do escândalo da razão sob o aspecto de que, por mais que contemos com a razão para alcançar a emancipação, é a própria razão que nos desencaminha quer para o dogma, quer para a incerteza (Azmanova, 2012).
} 


\section{A desaparecida crise do capitalismo}

Uma das peculiaridades do neoliberalismo em estado de morto-vivo é a perpetuação do discurso de crise. Estamos travados numa narrativa de crise já há uma década. À esquerda, há a antecipação e celebração de uma iminente crise terminal do capitalismo. À direita, isso toma a forma de uma narrativa sobre a indesejável desordem de um mecanismo econômico que é essencial para o bemestar das sociedades - algo que vale a pena salvar por meio da competência e da vontade das elites dominantes encarregadas da nobre missão de reparar o motor da prosperidade. Adentramos, assim, o âmbito do que o filósofo francês Jacques Derrida chama de "crise da crise" - ao mesmo tempo que a palavra "crise" se evade de nosso vocabulário, persiste a ideia de que o mundo presente está em crise (Derrida, 2002 [1983], p. 71). Para designar essa rara condição de uma crise que entra numa crise de si mesma, eu empregaria o termo "metacrise”. Elaboro essa noção a partir do conceito de "estado metaestável" de uma entidade, conceito usado na física e na química para descrever um particular estado energético de um sistema que tem uma duração mais breve que o menor nível de energia (ou nível fundamental), mas uma duração mais longa que o estado energético ordinário. ${ }^{7}$ Esse estado intermediário de agitação seria semelhante a um estado de febre baixa ou ansiedade persistente em que se encontrasse um organismo - que é como, de fato, se encontram nossas sociedades uma década depois do colapso financeiro de 2007-2009: as energias da experiência inicial de crise social foram dissipadas, mas a sociedade não recuperou seu senso de normalidade, de um bem-estar estável. Ela é atormentada por uma inflamação crônica; está em stásis - termo com o qual Tucídides retratara o alastramento do profundo conflito civil que bloqueava o fluxo normal da política democrática na pólis grega (Price, 2001).

Esse prolongado estado de crise desafia a própria definição de crise como um breve momento de extrema adversidade para a existência de uma entidade e que constitui um divisor de águas em sua vida. Há, em princípio, três possíveis saídas de uma crise: morte, restauração da condição anterior à crise ou transição para um novo estado. Estamos numa conjuntura histórica muito peculiar - nenhuma dessas três alternativas se aplica. As estratégias de resolução da crise financeira não resolveram a crise social mais ampla; remediar a crise apenas por um curto espaço de tempo tornou-se o novo normal - estamos travados numa perpétua gestão de crise. A radicalidade da crise é evitada, mas a própria crise não é resolvida. A crise mesma está numa crise: estamos travados numa metacrise.

\footnotetext{
7 Ver metastable state na Encyclopedia Britannica: https: / / www. britannica.com/science/metastablestate (acesso em: 9 abr. 2020). Agradeço a Victor Elgersma por ter apontado a semelhança entre a noção de "crise da crise" por mim usada em anteriores análises do capitalismo e a noção de um estado metaestável tal como usada na física.
} 
Uma das características do estado metaestável de um sistema (conforme a noção é usada na física) é particularmente adequada para o diagnóstico das democracias liberais atuais em seu estado de metacrise. Um estado metaestável é uma armadilha energética em que a entidade que nela se encontra não tem energia suficiente para transitar para outro estado. Isso evoca o encurralamento experienciado por nossas sociedades durante o período que se tornou conhecido como a Grande Recessão - a década após a crise de 2007-2009, década em que, ao mesmo tempo que a economia torna a crescer, uma sensação de mal-estar se alastra, mal-estar que, no entanto, não impele a qualquer tentativa de transformação radical.

\section{A deflação da utopia socialista}

Por que será que do fraturamento da hegemonia neoliberal não emanou qualquer alternativa? Por que nos encontramos travados numa metacrise justamente quando a sociedade está tão agitada de descontentamento? Um fator importante, que é antes constitutivo da metacrise do capitalismo do que causador dela, é a notável ausência de utopias - o que Jürgen Habermas aborda como "esgotamento das energias utópicas" - o desaparecimento de "possibilidades alternativas de vida que sejam compreendidas como inerentes ao próprio processo histórico" (Habermas, 1991 [1984], p. 50). Em sua discussão da crise do Estado de bem-estar social nos anos 1980, Habermas nota que, ao passo que não desapareceram completamente as antecipações utópicas que projetam o presente em direção a um futuro melhor, uma particular utopia se acabou - a utopia socialista que girava em torno da emancipação do trabalho do controle externo (Habermas, 1991 [1984], pp. 52-3). Nos últimos anos, todavia, a ideia de socialismo ressurgiu. A filiação à associação civil Democratic Socialists of America aumentou dez vezes entre 2016 e 2018 no próprio bastião do capitalismo - os Estados Unidos - , graças, em grande parte, aos socialistas da geração do milênio. ${ }^{8}$ Ainda assim, desacreditada pelos experimentos com o socialismo autocrático na antiga União Soviética e no Leste Europeu, a utopia socialista perdeu muito de sua capacidade para unir as diversas vertentes da animosidade anticapitalista. Para muitos, a ideia de socialismo (com as conotações que ela adquiriu após 1989) é um entrave à efetivação de seu apoio a políticas públicas anticapitalistas. Desse modo, paradoxalmente, o socialismo passou a ser, presentemente, um inconveniente para a mobilização anticapitalista. ${ }^{9}$

8 De acordo com uma pesquisa da YouGov de 2019, 70\% dos entrevistados pertencentes à geração do milênio se disseram relativa ou extremamente propensos a votar num candidato socialista na eleição presidencial de 2020: https: / / www.victimsofcommunism.org/2019-annual-poll (acesso em: 9 abr. 2020).

9 É com pesar que escrevo isso. Muitos dos dissidentes do Leste Europeu que combateram o socialismo autocrático fizeram-no em nome do comunismo liberal - uma posição que ainda perfilho. No entanto, o objeto de minha análise aqui é a situação histórica atual e o potencial de uma transformação anticapitalista nela contido. 
Em meio à crise econômica, as mobilizações políticas mais bem-sucedidas (no que se refere a ganhos eleitorais e repercussão em políticas públicas) são orientadas não por aspirações ao socialismo, mas antes por noções de patriotismo econômico e até xenofobia. Tais mobilizações coletivas são vazias de ambições utópicas. Ao mesmo tempo que as famílias políticas da esquerda e da direita mantêm sua liderança na política eleitoral, a fratura conflituosa não é mais a clássica divisão que opõe o capital ao trabalho, divisão que moldou o mapa da competição eleitoral desde a revolução industrial oitocentista. Essa clivagem foi gradualmente apagada sob a colaboração entre capital e trabalho em prol do crescimento, dos empregos e da redistribuição, uma colaboração forjada sob o arcabouço do Estado de bem-estar social do pósguerra. Recentemente, uma nova divisão veio à tona - uma divisão que reflete atitudes conflitantes em relação ao impacto social (percebido e antecipado) da nova economia de fronteiras abertas e alvoroçamento tecnológico. Aqueles que celebram a nova economia como sendo inerentemente progressista se congregam ao redor do polo da "oportunidade"; no lado oposto das barricadas, em volta do polo do "risco", reúnem-se aqueles para os quais a nova economia se traduz numa perda de meios de vida, em ameaças físicas e em fraturamento cultural (Azmanova, 2011b). Não há qualquer senso positivo de direção (uma utopia) nessas duas posições - nada parecido com o ideal socialista que guiara as erupções de 1848 e 1917, o anticonsumismo irreverente de 1968 e o comunismo liberal (a redenção e renovação do comunismo) que motivou, em grande medida, 1989. Nem as oportunidades nem os riscos da nova economia, ao passo que estruturam atualmente o conflito social, podem fornecer o material para utopias poderosas que pudessem orientar a imaginação coletiva na busca por uma nova ordem socioeconômica.

\section{Capitalismo da precariedade}

As razões do esgotamento das energias utópicas e da fraqueza da ação emancipatória que marcam nosso particular momento histórico dizem respeito à massiva desestabilização social que define o atual estágio do capitalismo - que descrevo como "capitalismo da precariedade" (Azmanova, 2020). Judith Butler (2004) traça a distinção entre a precariedade [precariousness] como uma condição humana geral de vulnerabilidade, enraizada na interdependência que temos uns dos outros, e a precariedade [precarity] socialmente gerada. Além disso, uma série de acadêmicos registra e discute a miséria causada pelo desemprego persistente e pelo emprego precário, o alastramento da pobreza entre a população empregada [in-work poverty] e, subsequentemente, a formação de uma nova classe, um "precariado" (que lembra o proletariado do século XIX) cujas remunerações são baixas, flexíveis 
e imprevisíveis (Apostolidis, 2018; Standing, 2011; Wright, 2019). ${ }^{10}$ Ao passo que a noção de precariedade tem sido reservada, até agora, apenas aos "perdedores" na distribuição de recursos econômicos, proponho vê-la como uma condição social abrangente que também afeta os supostos vencedores no jogo da produção de lucro. 0 ativo descarregamento do risco social na sociedade, ativamente empreendido pela autoridade pública durante os últimos quarenta anos, criou uma condição de precariedade social generalizada contra a qual os íntimos do mercado de trabalho - trabalhadores qualificados que dispõem de empregos de boa remuneração e proprietários de capital - não estão abrigados. Enquanto a desregulação do mercado de trabalho significou, para muitos, desemprego de longo prazo ou empregos instáveis e de má remuneração, ela se tornou, para outros, a fonte de empregos mais estressantes com mais horas de trabalho, comprometimento do equilíbrio entre trabalho e vida e danificação da saúde mental. Assim, o aumento das pressões competitivas do capitalismo globalmente integrado criou não apenas uma classe precária, mas uma multidão precária: a precariedade é o que está a afligir os $99 \%$ (Azmanova, 2020, pp. 137-68).

A condição de precariedade generalizada tem formidáveis consequências para as possibilidades de mudança social progressista. A instabilidade econômica, especialmente na ausência de utopias motivacionais, alimenta instintos conservadores e, amiúde, reacionários - uma atitude sociopsicológica que Erich Fromm (1941) aborda como "medo da liberdade". Embora a crise econômica de 2007-2009 tenha despertado, na esquerda, esperanças de que a radicalização dos protestos conduzisse a uma sublevação anticapitalista, conforme ressaltei acima, o voto democrático foi consistentemente para a direita na última década, dando expressão não a desejos de mudança radical, mas antes ao oposto - a um anseio por segurança e seguridade. Tendo emergido nas margens de extrema-direita do espectro político na virada do século, a agenda antiprecariedade de preocupações sociais com insegurança física (terrorismo), ordem política, estranhamento cultural e inseguridade econômica foi absorvida, nos últimos anos, pelos posicionamentos de partidos de centro-direita e até de alguns de centro-esquerda. ${ }^{11}$

Nesse contexto, a esquerda, ao reengajar-se na crítica social e na mobilização política, descreve duas trajetórias. Por um lado, um renascimento da política de

10 Guy Standing (2011, capítulo 3) ressalta que todo mundo pode entrar no precariado por circunstâncias não intencionadas ou por escolha pessoal. Paul Apostolidis $(2018$, p. 3) nota que as características das vidas precárias por ele registradas em seu estudo de trabalhadores diaristas de procedência latino-americana estão espalhando-se bem acima dos estratos da classe mais baixa: "Se 'precariedade' designa a especial desgraça dos seres humanos mais virulentamente oprimidos no mundo, também denota um complexo quase universal de não liberdade". Para um panorama abrangente do conceito, ver della Porta et al (2015).

11 Poderíamos relembrar, por exemplo, que o lema "Empregos britânicos para trabalhadores britânicos" foi cunhado pela liderança do Partido Trabalhista britânico. 
classe se expressa através de uma luta contra a desigualdade (os ricos representando os inimigos de classe). Por outro lado, clamores pela salvação da democracia servem como uma plataforma abrangente para as forças progressistas. No restante desta análise, sustentarei que essas duas trajetórias de mobilização não conduzirão a um projeto político emancipatório porque são derivadas de diagnósticos incorretos da presente conjuntura histórica e, portanto, são respostas inadequadas às emergências sociais de nosso tempo.

Abordemos, primeiro, o projeto de salvação e/ou radicalização da democracia. Em sua mais recente análise, Chantal Mouffe (2018, p. 41) observa que "os principais alvos do 'movimento das praças' foram os defeitos do sistema político e das instituições democráticas e que eles não clamaram por 'socialismo' nem por uma 'democracia real'". ${ }^{12}$ De fato, as oligarquias políticas e econômicas que emergiram durante os últimos trinta anos, bem como o ataque intensificado a valores liberais por movimentos protofascistas, infligiram um terrível dano a nossas democracias. É necessário agir urgentemente. Todavia, a infraestrutura política da democracia - das disputas eleitorais aos protestos de rua -, conforme ressaltei acima, também está dando expressão política a uma poderosa aliança entre capital e trabalho em apoio ao crescimento e aos empregos - uma aliança que sistematicamente bloqueia ou mina políticas públicas comprometidas com o meio ambiente. Se nos cabe alcançar tanto a justiça social como a justiça ambiental (as ambições do Green New Deal), não basta que radicalizemos a democracia, dado que tal radicalização tende apenas a fortalecer o poder político da aliança entre capital e trabalho contra o meio ambiente.

No entanto, também não seria proveitoso tentar romper a aliança entre capital e trabalho por meio do revigoramento do conflito de classes, tal como se tenta atualmente através de reivindicações pela tributação das fortunas e pela coletivização da propriedade. E não o seria porque apenas uma aliança muita ampla de forças sociais poderia alcançar, ao mesmo tempo, a justiça social e a justiça ambiental. Isso requereria não romper, mas subverter a aliança existente entre capital e trabalho - direcionando-a a uma transformação radical da maneira pela qual a sociedade reproduz a si mesma. Abordemos esse ponto mais detalhadamente.

\section{Subverter o capitalismo}

Em seu último livro, o eminente sociólogo marxista Erik Olin Wright passa revista em cinco modos (ou “lógicas estratégicas”) de mobilização anticapitalista

12 Em dezembro de 2018, uma ampla iniciativa de cidadãos lançou um "Manifesto pela democratização da Europa" - conhecido como "Plano Piketty" - que inclui um Tratado de Democratização para a Europa. Le Monde, 10 dez. 2018: https://www.lemonde.fr/blog/piketty/2018/12/10/manifestofor-the-democratisation-of-europe/ (acesso em: 20 abr. 2020). 
- esmagar, desmantelar, domar, resistir e escapar ao capitalismo (Wright, 2019). Essa taxonomia das estratégias anticapitalistas baseia-se numa compreensão do capitalismo como um sistema econômico que se define "pela combinação da troca no mercado com a propriedade privada dos meios de produção e a utilização de trabalhadores assalariados recrutados através de um mercado de trabalho" (Wright, 2019, p. (.886). Assim, as várias estratégias anticapitalistas examinadas por Wright têm como alvo mudanças no interior dessas estruturas nucleares do capitalismo e/ ou neutralizar danos produzidos por tais estruturas. Essas estratégias são levadas a efeito quer através de iniciativas de resistência ou escape ao capitalismo que, partindo de baixo para cima, giram em torno da sociedade civil; quer através de estratégias de domesticação e desmantelamento do capitalismo que, partindo de cima para baixo, giram em torno do Estado. Wright advoga uma nova configuração estratégica - a saber, erodir o capitalismo através da persistente construção de relações econômicas mais participativas, democráticas e igualitárias. Desse modo, o capitalismo haveria de ser, por fim, destituído de seu papel dominante no sistema (Wright, 2019, p. l.871).

A análise que Wright faz das possibilidades viáveis de transcender o capitalismo, ao mesmo tempo que faz avançar a crítica do capitalismo, ilustra as limitações das formas de marxismo atualmente prevalentes. Enquanto Marx aborda o capitalismo como um sistema de relações sociais organizadas em torno da relação-mercadoria (isto é, como um sistema que gira em torno da produção, da troca e do consumo de bens deliberadamente produzidos para o mercado, tendo em vista gerar lucro), a maior parte das abordagens contemporâneas do capitalismo reduzem-no às instituições estruturantes dessas relações - a saber, o trabalho assalariado e a propriedade privada dos meios de produção. Essas análises entendem que a superação final do capitalismo tem o trabalho socializado como sua principal questão. ${ }^{13}$

Esse conhecido cenário da política progressista é, porém, inadequado às exigências de nosso momento histórico. E o é porque, mesmo que os objetivos atualmente mais radicais da esquerda fossem alcançados - a erradicação da propriedade privada dos meios de produção (a principal instituição estruturante do capitalismo) -, isso não eliminaria automaticamente as formas extrativistas e destrutivas pelas quais a riqueza é produzida e consumida. As graves injustiças sociais de nosso tempo - a precariedade social generalizada, que abordei acima, e a devastação ambiental

$13 \mathrm{Em}$ minha própria obra, levo a efeito uma mudança de foco pela qual passo a centralizar, em vez dessas instituições estruturantes, a dinâmica da produção concorrencial de lucro, dinâmica que considero ser constitutiva do capitalismo e poder ocorrer mesmo sem as instituições estruturantes (Azmanova, 2014, 2018b, 2020). Trato o capitalismo como um sistema de relações sociais dotado de (1) uma dinâmica constitutiva: a produção concorrencial de lucro; (2) instituições estruturantes: por exemplo, a propriedade e administração privada dos meios de produção; e (3) efeitos distributivos. Ao passo que uma luta emancipatória deveria alvejar todas as três dimensões em que se dá a injustiça, a prática radical consiste em combater a dinâmica constitutiva (Azmanova, 2020, capítulo 2). 
- são produtos não da distribuição desigual da riqueza nem do caráter privado da detenção da propriedade (isto é, das instituições estruturantes do capitalismo e de seus resultados distributivos), mas da própria dinâmica que constitui o capitalismo a busca do lucro. Como o experimento com o socialismo de Estado no Leste Europeu e na Europa Central deixou claro, sociedades em que os meios de produção são detidos coletivamente e em que se distribuem recursos de modo relativamente igual ainda podem estar engajadas numa busca concorrencial de lucro, com todo seu deletério impacto sobre os seres humanos, sobre nossas comunidades e sobre nosso ambiente natural. Considerando as particulares exigências de nosso tempo, isso significa que nem a tradicional agenda social-democrata de redistribuição nem a agenda socialista de eliminação da propriedade privada miram nos alvos certos. É a eliminação da dinâmica funcional fulcral do capitalismo - a busca concorrencial de lucro - que deveria ser o objetivo central da ação política e da prática social radicais emancipatórias.

A fim de modificar a dinâmica nuclear da ordem social - o modo como a sociedade produz suas condições materiais e valoriza as realizações de seus membros -, e não simplesmente remediar os resultados distributivos injustos (a desigualdade) e eliminar as instituições estruturantes opressivas (a propriedade privada), deve efetuar-se uma mobilização bastante abrangente contra a dinâmica constitutiva do capitalismo - a produção de lucro. A luta de classes como uma estratégia de mobilização anticapitalista que a esquerda está reanimando agora seria incapaz de alcançar tal frente anticapitalista ampla e até poderia obstaculizar sua formação. Precisamos de uma estratégia alternativa para a política radical, uma estratégia que denomino de subversão do capitalismo a partir de dentro dele mesmo - ou seja, tomar a aliança existente entre capital e trabalho e direcioná-la contra as pressões concorrenciais da produção de lucro.

Para realizar tal subversão, devemos conectar a multiplicidade de agravos que atravessam a divisão que opõe o capital ao trabalho (uma divisão moldada em função da propriedade e administração dos meios de produção) por meio de um denominador comum. Esse denominador comum ajudaria a construir uma singular “cadeia de equivalências" (Mouffe \& Laclau, 1985) entre os vários agravos. Uma lógica de equivalência entre as diversas experiências de dano social está disponível agora no fenômeno da precariedade social generalizada, que abordei acima. Conforme ressaltei, experiências de injustiça conflitantes (por exemplo, o desemprego crônico ou o emprego instável que aflige os trabalhadores de baixa qualificação versus o equilíbrio ruim entre trabalho e vida para os detentores de bons empregos) têm uma raiz comum - elas se originam na intensificação das pressões exercidas pela busca do lucro sob o arcabouço de mercados globalmente integrados. A dinâmica do capitalismo contemporâneo gera, assim, uma oposição abrangente aos processos 
pelos quais a abundância é criada, independentemente da particular distribuição dessa abundância e das formas de detenção da propriedade mediante as quais ela é criada.

O capitalismo contemporâneo gera essa ampla oposição através de duas contradições internas (antinomias). A primeira, que denomino de "excedente de empregabilidade", consiste no aumento do potencial de desmercadorização das sociedades modernas e no simultâneo aumento das pressões de mercadorização. ${ }^{14}$ A segunda contradição - a "dependência aguda do emprego" - é gerada pela tensão entre a redução da disponibilidade de bons empregos e o aumento da dependência de um emprego como uma fonte de sustento. Uma vez que essas antinomias criam uma vida de precariedade social mesmo para os vencedores na distribuição desigual da abundância, elas proporcionam a base para uma ampla aliança anticapitalista (Azmanova, 2020, pp. 147, 151).

As instituições estruturantes do capitalismo - as formas de detenção da propriedade e de manutenção do emprego - funcionam como condições possibilitadoras em relação ao processo de subversão do capitalismo. Por um lado, a aliança entre capital e trabalho que atualmente apoia a agenda de políticas públicas orientadas para o crescimento e os empregos (e que, assim, esteia o capitalismo) foi reforçada pela “democratização” da detenção da propriedade - dado que a detenção de participações em empresas de capital aberto não só se tornou amplamente acessível, mas tornouse, através dos investimentos de fundos de pensão nessas participações, ubíqua e inevitável. Por outro lado, porém, isso alterou o equilíbrio entre oportunidades e riscos que as estruturas de propriedade criam. No contexto do capitalismo "clássico" do século XIX, contexto em que Marx escrevia, a propriedade privada dos meios de produção proporcionava vantagens econômicas aos proprietários de capital e, ao mesmo tempo, abrigava-os contra os riscos sociais que tomar parte na busca do lucro implica. Os riscos corriam por conta do trabalho assalariado (que não se beneficiava das proteções desfrutadas pela detenção da propriedade). Formas ortodoxas de marxismo ainda trabalham com essa ontologia do capitalismo, que é a base de que se servem para prescreverem a socialização do trabalho (isto é, a eliminação do princípio da detenção privada dos meios de produção) como a solução apropriada.

No contexto atual, porém, a fórmula predominante de detenção da propriedade,

14 A autora formula mais claramente o "excedente de empregabilidade" na seguinte passagem de seu mais recente livro: "[A primeira das duas principais contradições do capitalismo contemporâneo] surge na tensão entre, de um lado, a capacidade tecnológica sem precedente que nossas sociedades têm para produzirem prosperidade material com mínima utilização do trabalho humano como fator produtivo (o que descrevo como o significativo potencial de desmercadorização de nossas sociedades) e, de outro, o crescimento constante das pressões para que nos mantenhamos empregados e empregáveis (isto é, o aumento das pressões de mercadorização)" (Azmanova, 2020, p. 192). O tradutor agradece ao(à) parecerista anônimo(a) por ter chamado sua atenção para a clarificação que essa passagem propicia. (N. T.) 
a saber, a detenção de participações em empresas de capital aberto, expõe todos os participantes aos riscos da busca concorrencial de lucro, sem as proteções que a propriedade exclusiva proporciona. Isso está entre as fontes mais fortes do fenômeno de precariedade social que abordei acima como uma característica fulcral do capitalismo contemporâneo - os riscos sociais gerados no curso da busca do lucro (da saúde mental deteriorada ao dano ambiental) superam os benefícios desse processo (o aumento da abundância). Isso significa que a principal instituição estruturante do capitalismo - a da propriedade privada dos meios de produção -, em sua forma atual, poderia servir como uma alavanca para construir uma aliança entre capital e trabalho contra o capitalismo, para subverter o capitalismo.

Forjar tal aliança de dois verdadeiros estranhos que, contudo, estão no mesmo barco, uma aliança contrária à própria lógica constitutiva do capitalismo - a produção concorrencial de lucro -, não necessitaria de uma crise terminal do capitalismo. Também não requereria que os participantes abraçassem uma utopia positiva (por exemplo, socialismo ou comunismo). Tal empreendimento anticapitalista se realizaria não através de estupendos gestos políticos de derrubada de um regime, mas antes empregaria o pragmatismo radical subversivo ${ }^{15}$ de práticas e políticas públicas simples que vão contra o motivo do lucro - da renda básica universal ao emprego repartido [job sharing] e ao investimento público em pesquisa científica. Combater a dinâmica funcional do capitalismo (a produção de lucro), em vez de desmantelar suas instituições estruturantes (a propriedade privada), é tanto um curso de ação mais radical como um programa mais realista para uma política transformadora - um programa que é o mais adequado às exigências de nosso momento histórico.

\section{Referências}

Apostolidis, P. (2018). The fight for time: migrant day laborers and the politics of precarity. Oxford: Oxford University Press.

Azmanova, A. (2011a). Against the politics of fear: on deliberation, inclusion, and the political economy of trust. Philosophy and Social Criticism, 37 (2), pp. 401-12.

Azmanova, A. (2011b). After the left-right (dis)continuum: globalization and the remaking of Europe's ideological geography. International Political Sociology, 5 (4), pp. 384-407.

Azmanova, A. (2012). The scandal of reason: a critical theory of political judgment. New York: Columbia University Press.

Azmanova, A. (2014). Crisis? capitalism is doing very well. How is critical theory? Constellations: an International Journal of Critical and Democratic Theory, 21 (3), pp. 351-65.

Azmanova, A. (2018a). The populist catharsis: on the revival of the political.

15 Sou grata a Claus Offe por ter dado à minha posição o apropriado rótulo de "pragmatismo radical subversivo" (ver Azmanova, 2020, contracapa). 
Philosophy and Social Criticism, 44 (4), pp. 399-411.

Azmanova, A. (2018b). Relational, structural and systemic forms of power: the "right to justification" confronting three types of domination. Journal of Political Power, 11 (1), pp. 68-78.

Azmanova, A. (2019). The emancipation paradox: populism, democracy, and the soul of the left. Philosophy and Social Criticism, 45 (9-10), pp. 1186-207.

Azmanova, A. (2020). Capitalism on edge. How fighting precarity can achieve radical change without crisis or utopia. New York: Columbia University Press.

Butler, J. (2004). Precarious life: the powers of mourning and violence. New York: Verso.

Dean, J. (2009). Democracy and other neoliberal fantasies: communicative capitalism and left politics. Durham: Duke University Press.

Della Porta, D., Hänninen, S., Siisiäinen, M., \& Silvasti, T. (2015). The precarization effect. In (Orgs.), The new social division: making and unmaking precariousness (pp. 1-23). London: Palgrave Macmillan.

Derrida, J. (2002 [1983]). Economies of the crisis. In Rottenberg, E. (Org.), Negotiations: interventions and interviews, 1971-2001 (pp. 69-73). Translated by Elizabeth Rottenberg. Stanford: Stanford University Press.

Fraser, N. (2017a). Against progressive neoliberalism, a new progressive populism. Dissent. Recuperado de: https://www.dissentmagazine.org/online_articles/ nancy-fraser-against-progressive-neoliberalism-progressive-populism. Acesso em: 9 abr. 2020.

Fraser, N. (2017b). The end of progressive neoliberalism. Dissent. Recuperado de: https://www.dissentmagazine.org/online_articles/progressive-neoliberalismreactionary-populism-nancy-fraser. Acesso em: 9 abr. 2020.

Fromm, E. (1941). Escape from freedom. New York: Farrar and Rinehart.

Habermas, J. (1991 [1984]). The new obscurity: the crisis of the welfare state and the exhaustion of utopian energies. In Nicholsen, S. W. (Ed.), The new conservatism. Cultural criticism and the historians' debate (pp. 48-70). Translated by Shierry Weber Nicholsen. Cambridge: MIT Press.

Kant, I. (1967). Philosophical correspondence 1759-99. Edited and translated by Arnulf Zweig. Chicago: University of Chicago Press.

Kant, I. (2007 [1781]). Critique of pure reason. 2nd rev. ed. Translated by Norman Kemp Smith. New York: Palgrave Macmillan.

Mouffe, C. (2018). For a left populism. London: Verso.

Mouffe, C., \& Laclau, E. (1985). Hegemony and socialist strategy. London: Verso.

Odendahl, C. (2017). The Hartz myth. A closer look at Germany's labour market reforms. London: Centre for European Reform. Recuperado de: https: / /www. cer.eu/sites/default/files/pbrief german_labour_19.7.17.pdf. Acesso em: 9 abr. 2020.

Price, J. J. (2001). Thucydides and internal war. Cambridge: Cambridge University Press. 
Rhodes, M. (2001). The political economy of social pacts: competitive corporatism and European welfare reform. In Pierson, P. (Ed.), The new politics of the welfare state (pp. 165-94). Oxford: Oxford University Press.

Standing, G. (2011). The precariat: the new dangerous class. London: Bloomsbury.

Streeck, W. (1984). Neo-corporatist industrial relations and the economic crisis in West Germany. In Goldthorpe, J. H. (Ed.), Order and conflict in contemporary capitalism (pp. 291-314). Oxford: Oxford University Press.

Wright, E. O. (2019). How to be an anticapitalist in the twenty-first century. New York: Verso.

Recebido em: 21.04.2020

Aceito em: 01.06.2020 